\title{
UM MAPEAMENTO SISTEMÁTICO SOBRE APONTAMENTOS DE INCLUSÃO NO BRASIL DURANTE O PERÍODO PANDÊMICO
}

\author{
José Gomes da Silva Filho \\ Especialista em Docência e Gestão do Ensino Superior pela Universidade Estácio de Sá (UNESA). \\ Aluno do curso de Pedagogia da Universidade Federal do Piauí (UFPI). \\ https://orcid.org/0000-0002-6676-4113 \\ Jayne de Sousa Silva \\ Aluna do curso de Pedagogia da Faculdade de Educação do Piauí (FAEPI). \\ Professora de Atendimento Educacional Especializado (AEE) da Prefeitura de Piracuruca/PI. \\ https://orcid.org/0000-0002-4639-950X
}

Data de submissão: 02/10/2020

Data de aprovação: 25/10/2020

\section{RESUMO}

Objetivou-se descrever, no presente artigo, o que a literatura aborda acerca da inclusão no Ensino Remoto Emergencial (ERE). Para tanto, a metodologia utilizada foi o mapeamento sistemático da literatura, cujas bases de dados Scielo, Google Acadêmico e Portal de Periódicos da CAPES foram acessadas utilizando os descritores: "ensino remoto" "deficiência" "inclusão", levando-se em consideração os seguintes critérios de inclusão: artigos científicos devidamente publicados em periódicos, entre janeiro a agosto de 2020, escritos em português e que sua abordagem central fosse sobre medidas de inclusão no ERE. Enquanto critérios de exclusão: aqueles que não fossem artigos científicos, escritos em língua estrangeira ou que não tratassem de medidas de inclusão no ERE. A busca retornou o total de 37 trabalhos, em que, depois de serem passados pelos critérios de elegibilidade, o total selecionado para compor o corpus deste estudo foram apenas 4 artigos. Observou-se que os trabalhos retornados se preocupam em abordar, sobremaneira, meios de viabilizar o acesso à educação quanto a deficiência visual, auditiva e outras perspectivas de inclusão com a utilização de recursos tecnológicos, apesar de algumas limitações, além de apresentarem entraves relacionados ao aspecto financeiro da família dos estudantes, a falta de acompanhamento dos pais, o despreparado docente frente às tecnologias, as especificidades que cada deficiência demanda e o próprio isolamento. Contudo, os resultados mostraram-se incipientes para se ter uma visão mais aprofundada sobre a inclusão no ERE, ensejando futuras pesquisas com um número maior de bases.

Palavras-chave: Inclusão. Deficiência. COVID-19. Ensino Remoto Emergencial.

\section{A SYSTEMATIC MAPPING ON POINTS OF INCLUSION IN BRAZIL DURING THE PANDEMIC PERIOD}

\section{ABSTRACT}

This paper aims to describe what the literature addresses about inclusion in Emergency Remote Education (ERE). For that, the methodology used was the systematic mapping of the literature, whose databases Scielo, Google Scholar and CAPES Journals Portal were accessed using the descriptors: "remote teaching" "disability" "inclusion", taking into account the following inclusion criteria: scientific articles duly published in journals, between January and August 2020, written in Portuguese and that their central approach was on inclusion 
measures in the ERE. As exclusion criteria: those that were not scientific articles, written in a foreign language or that did not deal with inclusion measures in the ERE. The search returned a total of 37 papers, in which, after being passed the eligibility criteria, the total selected to compose the corpus of this study were only 4 articles. It was observed that the works returned are concerned with addressing, above all, ways of enabling access to education regarding visual, hearing impairment and other inclusion perspectives with the use of technological resources, despite some limitations, in addition to presenting barriers related to financial aspect of the students' family, the lack of parental support, the unprepared teacher in face of technologies, the specificities that each disability demands and the isolation itself. However, the results proved to be incipient in order to have a more in-depth view of inclusion in the ERE, giving rise to future research with a greater number of bases.

Keywords: Inclusion. Deficiency. COVID-19. Emergency Remote Teaching.

\section{UN MAPEO SISTEMÁTICO DE LOS PUNTOS DE INCLUSIÓN EN BRASIL DURANTE EL PERIODO DE PANDEMIA}

\section{RESUMEN}

El objetivo de este artículo fue describir lo que la literatura aborda sobre la inclusión en la Educación Remota de Emergencia (ERE). Para ello, la metodología utilizada fue el mapeo sistemático de la literatura, en la cual se accedió las bases de datos Scielo, Google Académico y el Sitio de Periódico de CAPES utilizando los descriptores: "enseñanza remota" "discapacidad" "inclusión", teniendo en cuenta los siguientes criterios de inclusión: artículos científicos debidamente publicados en revistas, entre enero y agosto de 2020 , textos en portugués y que su enfoque central fuera sobre medidas de inclusión en ERE. Como criterios de exclusión: aquellos que no fueran artículos científicos, redactados en lengua extranjera o que no abordaran medidas de inclusión en ERE. La búsqueda apuntó el total de 37 trabajos científicos, en los cuales, luego de pasar los criterios de elegibilidad, el total seleccionado para componer el corpus de este estudio fue de solo 4 artículos. Se observó que los trabajos identificados están preocupados por abordar, sobre todo, formas de posibilitar el acceso a la educación en materia de discapacidad visual, auditiva y otras perspectivas de inclusión con el uso de recursos tecnológicos, a pesar de algunas limitaciones, además de presentar barreras relacionadas con aspecto económico de la familia de los alumnos, la falta de acompañamiento de los padres, la falta de preparación de los docentes ante las tecnologías, las especificidades que demanda cada discapacidad y el aislamiento en sí. Sin embargo, los resultados demostraron ser incipientes para tener una visión más profunda de la inclusión en ERE, dando lugar a futuras investigaciones con mayor número de bases.

Palabras clave: Inclusión. Discapacidad. COVID-19. Enseñanza remota de emergencia.

\section{INTRODUÇÃO}

A pandemia do novo coronavírus acarretou impactos sociais significativos em todo o mundo. De igual modo, observou-se na sociedade brasileira, cujas áreas da economia, saúde e educação foram as mais comprometidas (SENHORAS, 2020a; SENHORAS, 2020b; LANA et al., 2020). Quanto a esta última, o Ensino Remoto Emergencial (ERE) foi utilizado como alternativa, entretanto, tal atitude revelou-se, em partes, relevante, uma vez que acentuou desigualdades no acesso à educação, porque mesmo com a tecnologia de "fácil acesso", esta, infelizmente, não é condizente com a realidade de toda a população brasileira (BARBOSA; CUNHA, 2020). 
Em uma pesquisa realizada em 2018, pelo Instituto Brasileiro de Geografia e Estatística (IBGE), foi revelado que cerca de 46 milhões de pessoas não possuíam acesso à internet, cujas classes mais abastadas representaram $96,5 \%$ do acesso, em detrimento de $59 \%$ dos acessos pelas classes menos abastadas (BARBOSA; CUNHA, 2020; IBGE, 2018). Estes dados fundamentam as desigualdades observadas no acesso ao ERE no período pandêmico, ao passo que denuncia a debilidade econômica que parte da população brasileira se encontra. Ademais, Saraiva, Traversini e Lockmann (2020, p.18) acrescentam sobre tais impactos, que "a migração das atividades escolares vem manter ou até aprofundar os processos de exclusão, seja de acesso à rede, seja de condição de realização das atividades nas casas dos estudantes e até de sobrevivência, como alimentação".

Partindo desse contexto e de estudos pregressos sobre os impactos do ERE à educação, como o de Silva Filho, Montalvão Neto e Rocha (2020), alarga-se ainda mais as reflexões quando se pensa a respeito da inclusão de pessoas com deficiências no ERE. Se, por um lado, existe o entrave da falta de acesso ao ensino remoto por parte da sociedade brasileira pelo fator financeiro, é pertinente questionar-se quanto ao suporte e inclusão desses sujeitos nesse momento pandêmico.

A opção acerca do tema proposto justifica-se pela crescente demanda por atendimento às pessoas com deficiências na educação, pois os dados do Censo Escolar de 2018 revelam um progressivo número de matrículas escolares de alunos com deficiências, transtornos globais do desenvolvimento ou altas habilidades, chegando a 1,2 milhão em 2018, representando um aumento de 33,2\% em relação a 2014 (INEP, 2019). Isso implica dizer que em meio a uma pandemia, cujo acesso à educação é dispare, o sistema educacional brasileiro conta com um contingente de pessoas com limitações, que, possivelmente, também estão alijadas quanto ao seu direito à educação (SILVA; BINS; ROZEK, 2020).

Nesse contexto, a problemática em questão gira em torno da seguinte pergunta: o que as publicações científicas, de janeiro a agosto de 2020, apontam sobre o que está sendo realizado para promover a inclusão dos alunos com deficiência no ERE? Diante disso, o presente artigo, de caráter descritivo, objetivou realizar um mapeamento sistemático da literatura a partir de artigos científicos, disponibilizados nas bases de dados Scielo, Google Acadêmico e Portal de Periódicos da CAPES, considerando o intervalo de janeiro a agosto de 2020, buscando apresentar os apontamentos levantados por essas publicações sobre inclusão no ERE.

\section{REFERENCIAL TEÓRICO}

\subsection{Educação especial para inclusão}

A mobilização da sociedade, em prol das pessoas com deficiências, influenciou a formulação de políticas públicas em defesa de seus direitos, possibilitando sua inserção num efetivo convívio social. O Estado assumiu a responsabilidade e a obrigação de desenvolver um conjunto de leis para atender às suas necessidades cada vez mais emergentes (ROCHA et al., 2018).

A Educação Especial se organizou tradicionalmente como Atendimento Educacional Especializado substituindo o ensino comum, que, por consequência, criou paradigmas acerca desse ensino, levando à criação de instituições e escolas especializadas para atender esses indivíduos (MINISTÉRIO DA EDUCAÇÃO, 2008). Acerca disso, Glat e Fernandes (2005, p. 01) afirmam que:

A Educação Especial se constituiu originalmente como campo de saber e área de atuação a partir de um modelo médico ou clínico. Embora hoje bastante criticado, é 
preciso resgatar que, como lembra Fernandes (1999), os médicos foram os primeiros que despertaram para a necessidade de escolarização dessa clientela que se encontrava "misturada" nos hospitais psiquiátricos, sem distinção de idade, principalmente no caso da deficiência mental. Sob esse enfoque, a deficiência era entendida como uma doença crônica, e todo o atendimento prestado a essa clientela, mesmo quando envolvia a área educacional era considerado pelo viés terapêutico. A avaliação e identificação eram pautadas em exames médicos e psicológicos com ênfase nos testes projetivos e de inteligência, e rígida classificação etiológica (GLAT; FERNANDES, 2005, p. 01).

Evidencia-se, portanto, que em seu princípio, a Educação Especial utilizava metodologias diferentes, isoladas das demais empregadas nas outras áreas de ensino comum. Não era vista, essencialmente, como uma forma de ensino, pois, como exposto, eram feitas avaliações, apresentadas como análises e estudos, buscando identificar as causas acerca das determinadas deficiências. Contudo, esse quadro foi se modificando quando houve a criação de duas instituições:

No Brasil, o atendimento às pessoas com deficiência teve início na época do Império, com a criação de duas instituições: o Imperial Instituto dos Meninos Cegos, em 1854, atual Instituto Benjamin Constant - IBC, e o Instituto dos Surdos Mudos, em 1857, hoje denominado Instituto Nacional da Educação dos Surdos - INES, ambos no Rio de Janeiro (MINISTÉRIO DA EDUCAÇÃO, 2008, p. 10).

A partir da Constituição Federal de 1988, como consta no artigo 205, a educação constitui-se como direito de todos e para todos, objetivando qualificar os cidadãos para 0 convívio social, bem como para o exercício profissional, ainda que tecnicista. A frente, no artigo 206, dispõe de alguns princípios para o ensino, dentre os quais se destacam a igualdade de condições e o ensino público gratuito (BRASIL, 1988).

Em 9 de janeiro de 2001 foi criado o Plano Nacional de Educação (PNE), pela Lei $n^{\circ}$ 10.172. No seu capítulo VIII discorre sobre a Educação Especial, apontando que as pessoas com deficiências receberam educação na rede regular, visando, dessa forma, a integração desses indivíduos na esfera educacional. Tinha em vista, ainda, a construção de escolas inclusivas que garantisse 0 atendimento à toda diversidade humana (MINISTÉRIO DA EDUCAÇÃO, 2001).

Por meio de todo esse processo de implementação da inclusão no âmbito educacional, a Educação Especial passa a ser uma modalidade de educação, assim como prevê o Parecer CNE/CEB 17/2001:

Educação Especial: Modalidade da educação escolar; processo educacional definido em uma proposta pedagógica, assegurando um conjunto de recursos e serviços educacionais especiais, organizados institucionalmente para apoiar, complementar, suplementar e, em alguns casos, substituir os serviços educacionais comuns, de modo a garantir a educação escolar e promover o desenvolvimento das potencialidades dos educandos que apresentam necessidades educacionais especiais, em todas as etapas e modalidades da educação básica (MINISTÉRIO DA EDUCAÇÃO, 2001, p. 18).

Em 2015 foi promulgada a Lei $n^{\circ} 13.146$, de 6 de julho de 2015, sendo por esta instituída a Lei Brasileira de Inclusão da Pessoa com Deficiência (Estatuto da Pessoa com Deficiência). No seu artigo 28, capítulo IV, sobre o direito à educação, assegura:

[...] II - aprimoramento dos sistemas educacionais, visando a garantir condições de acesso, permanência [...] e promovam a inclusão plena;

III - projeto pedagógico que institucionalize 0 atendimento educacional especializado [...];

$\mathrm{V}$ - adoção de medidas individualizadas e coletivas em ambientes que maximizem o desenvolvimento acadêmico e social dos estudantes com deficiência, favorecendo o acesso, a permanência, a participação e a aprendizagem em instituições de ensino (BRASIL, 2015, p. 07). 
Recentemente houve a extinção da Secretaria de Educação Continuada, Alfabetização, Diversidade e Inclusão (SECADI) por meio do Decreto $\mathrm{n}^{\circ}$ 9.465, de 2 de janeiro de 2019. Em compensação, foi criada a Secretaria de Modalidades Especializadas de Educação (SEMESP), que tem a intenção de vincular as políticas da educação especial com os demais sistemas de ensino (BRASIL, 2019; TODOS PELA EDUCAÇÃO, 2020; MINISTÉRIO DA EDUCAÇÃO, 2020).

Constata-se que a inclusão de políticas públicas para a Educação Especial é recente no contexto social. Ligada ao conceito de educação para todos, impõe-se o dever de proporcionar uma educação de qualidade, salientando-se que as políticas de inclusão não se resumem somente ao ambiente escolar e visam dedicar-se ao preparo profissional desses indivíduos. Entretanto, apesar dos estímulos da legislação acerca de garantir os direitos destinados às pessoas com deficiências, existem muitas barreiras a serem enfrentadas, e, atualmente, isso pode ter sido mais comprometido pelo contexto epidêmico que é vivido. Diante disso, retorna-se à indagação inicial sobre o que se tem feito para a inclusão de pessoas com deficiências no ERE.

\subsection{Ensino Remoto Emergencial para inclusão?}

Inicialmente, é pertinente destacar que há diferença entre o ERE e o Ensino a Distância (EAD). O EAD configura-se como um sistema de formação robusto, bem projetado e articulado, de modo que o acesso à educação seja satisfatório. Em contrapartida, o ERE é uma forma de ensino temporário e alternativo daquele que havia sido planejado para ser realizado presencialmente. Este, atualmente, foi empregado no sistema educacional brasileiro, por força da pandemia do novo coronavírus, entretanto deu margens para se pensar sobre o acesso ao ensino no período pandêmico vivenciado (HODGES et al., 2020).

Ademais, o ERE não se deu de igual modo entre as instituições públicas e privadas, sendo essa realidade observada em todas as modalidades, do ensino básico ao superior. Essa alternativa educacional, a princípio, foi tomada pelas organizações privadas, pelo fato de muitas já disporem da oferta do EAD, sendo para elas uma maneira de amenizar os impactos econômicos sofridos. Em compensação, as instituições públicas não ofereceram o ERE de pronto, por razão de não terem uma infraestrutura adequada para tanto, sendo que o contexto foi ainda mais intensificado, uma vez que muitas pessoas sequer possuíam condições financeiras para manter internet em seus lares a fim de continuarem com seus estudos (BARBOSA; CUNHA, 2020).

O impacto do COVID-19, no ensino básico, pode ser ilustrado com o caso de um estudo realizado na cidade de Bayeux, no estado da Paraíba. A pesquisa destaca que as questões sociais, econômicas e culturais foram os aspectos centrais que dificultaram a participação dos alunos no ERE, seja pela falta de recursos digitais, desinteresse ou traquejo pedagógico dos pais para acompanharem os filhos. Destaca ainda, que o fazer pedagógico do professor foi muito impactado, pois tiveram que adaptar sua forma de conduzir as aulas. Além de buscarem formas de manter o interesse dos alunos e superarem as próprias limitações em lidar com a tecnologia, de modo a contemplar as exigências curriculares, nos casos de professores que tivessem alunos com deficiências visual ou auditiva, tinham que promover, simultaneamente, a inclusão, como destacou o plano de trabalho da Secretaria de Educação da cidade supracitada. Entretanto, ressalta que estes empenharam-se e ofereceram o que estava em seu alcance (SILVA, 2020).

A seu turno, no Ensino Superior, observou-se que no estudo realizado por Bezerra et al. (2020), ao se reportar sobre o ERE em instituições públicas estaduais, onde essa modalidade de ensino é oferecida, mesmo com $50 \%$ delas no Brasil operando no ERE, o 
ensino ocorre com incertezas metodológicas, o que pode comprometer a qualidade do aprendizado, e por sua vez, a formação acadêmica dos discentes, uma vez que tanto alunos como professores precisam adequar-se à nova demanda de ensino e aprendizagem.

Esses impactos na aprendizagem pesam, sobremaneira, aos cursos que exigem uma prática constante e rigorosa, como os da área da saúde, por exemplo. Nesse sentido, - ERE e o EAD são modalidades de ensino que mostram-se satisfatórias, momentaneamente, durante a pandemia, embora deixem lacunas no processo formativo desses profissionais. Portanto, tais formatos educacionais não são viáveis para uma formação completa e consistente dos especialistas da referida área (COSTA et al., 2020).

Em contrapartida, tal contexto também é preocupante quanto à inclusão, o qual se faz urgente que na educação todos tenham acesso ao ensino, em que políticas públicas e mesmo atitudes pessoais pró inclusão, principalmente de professores, sejam efetivas. Böck, Gomes e Beche (2020, p. 139) assinalam que "isso deve ser pensado para além das políticas públicas, no sentido de que as atitudes individuais devem trazer a premissa do cuidado no acolhimento a todos os estudantes, sem exceções".

Diante disso, fica evidente que foram muitos os impactos da pandemia no ensino. Ademais, é preciso destacar que a educação no pós pandemia não será a mesma de outrora, requerendo mobilizações de políticas públicas que atendam tanto alunos como professores, a fim de que o direito à educação seja cumprido, especialmente daqueles discentes com alguma deficiência ou limitação de aprendizagem (OLIVEIRA et al., 2020).

\section{METODOLOGIA}

Trata-se de uma pesquisa descritiva sobre as publicações realizadas entre o período de janeiro a agosto de 2020 no que tange ao ERE e a inclusão de pessoas com deficiências. Para tanto, realizou-se um mapeamento sistemático da literatura, que de acordo com Rocha, Nascimento e Nascimento (2018, p. 01) "é um método para construir um esquema de classificação e estruturar um tema de pesquisa". Este método segue três etapas: a primeira dá-se com a formulação do objetivo e questão orientadora do mapeamento; a segunda pela definição dos critérios de inclusão e exclusão dos trabalhos que irão compor o corpus de análise da pesquisa, assim como o delineamento de descritores de busca, bases de dados para retirada dos trabalhos e definição de requisitos para extração das amostras para análise, se por título, resumo ou trabalho completo e a terceira etapa é feita pela tabulação, análise e apresentação do mapeamento (ROCHA; NASCIMENTO; NASCIMENTO, 2018).

Seguindo a metodologia apresentada, inicialmente formulou-se a seguinte questão norteadora: o que as publicações científicas, de janeiro a agosto de 2020, apontam sobre o que está sendo realizado para promover a inclusão dos alunos com deficiências no ERE? Partindo para a segunda etapa e já de posse do questionamento supramencionado, optouse por eleger os seguintes critérios de elegibilidade: artigos científicos devidamente publicados em periódicos, entre janeiro a agosto de 2020, escritos em português e que sua abordagem central fosse sobre medidas de inclusão no ERE. Enquanto critérios de exclusão: aqueles que não fossem artigos científicos, escritos em língua estrangeira ou que não tratassem de medidas de inclusão no ERE. As bases de dados acessadas foram a Scielo, Google Acadêmico e Portal de Periódicos da CAPES, utilizando-se dos descritores: "ensino remoto" "deficiência" "inclusão". Os trabalhos, inicialmente, foram analisados pelos títulos e resumos, os que se enquadraram nos critérios de inclusão foram exportados para o Endnote, que segundo Estorniolo Filho (2018), é um programa de acesso livre que possibilita o armazenamento e a organização dos trabalhos resultantes de buscas em bases de dados e sua possível citação e referência automática em um texto. Com isso, o 
gerenciador de referências colaborou na organização dos dados, facilitando, posteriormente, na leitura e referenciação dos artigos selecionados. Além disso, após a leitura minuciosa de cada artigo seria feita uma segmentação dos mesmos por deficiência e método utilizados, no entanto, pelo número reduzido, não foi exequível categorizá-los de tal modo. E, seguindo a terceira fase do mapeamento sistemático, após a leitura e análise dos artigos, o relatório foi apresentado em forma de um texto descritivo.

\section{ANÁLISE E DISCUSSÃO DOS RESULTADOS}

A busca inicial retornou 37 resultados no Google Acadêmico e nenhum no Portal de Periódico da CAPES e Scielo. Após aplicação dos critérios de elegibilidade, anteriormente apresentados na metodologia, selecionou-se apenas 4 artigos para fazer parte do corpus de análise deste trabalho. Notou-se que Bonotto et al. (2020) trata da Comunicação Aumentativa e Alternativa; Leite et al. (2020) apresentou as dificuldades de alunos com deficiência visual na graduação; Shimazaki, Menegassi e Fellini (2020), o ensino remoto para os surdos e Böck, Gomes e Beche (2020) buscou estudar a experiência da deficiência em si, na pandemia.

\subsection{Bonotto et al. (2020): Oportunidades de aprendizagem com apoio da Comunicação Aumentativa e Alternativa em tempos de Covid-19}

O trabalho analisa conteúdos de postagens abordando sobre a Comunicação Aumentativa e Alternativa na página "comunicatea_pais" na rede social Instagram, com o intuito de identificar o que estava sendo criado e apresentado quanto ao apoio da aprendizagem de estudantes com Necessidades Complexas de Comunicação, durante o fechamento das escolas devido à pandemia pelo novo coronavírus. A escolha da página se deu pela frequência de postagens sobre o tema, maior número de inscritos e diversidade de materiais. A página é um grupo formado por pais de crianças no espectro do autismo com Necessidades Complexas de Comunicação, sendo uma iniciativa ligada ao grupo de estudos ComunicaTEA12 (BONOTTO et al., 2020).

O processo de Análise de Conteúdo feita envolveu 174 postagens, deu-se por meio das etapas de pré-análise, exploração do material e tratamento dos resultados, destacandose cinco categorias: orientações sobre a Covid-19; atividades educativas formais; atividades educativas não formais; orientações sobre o uso de Comunicação Aumentativa e Alternativa e recursos tecnológicos. Iniciou-se o descarte de postagens que não ofereciam uma contribuição educacional e assim, para a análise de dados, foram consideradas 94 postagens. Os materiais postados demonstraram a contribuição da página em divulgar informações e diminuir desigualdades ao promover o acesso a recursos de apoio à comunicação. Constata-se um processo dinâmico de apoio educacional e psicossocial para a comunidade de pessoas com Necessidades Complexas de Comunicação e sua rede de apoio frente às mudanças na rotina escolar (BONOTTO et al., 2020).

\subsection{Leite et al. (2020): Impactos da Covid-19 na graduação da pessoa com deficiência visual}

O presente estudo discute as modificações do contexto educacional no ensino superior decorrentes da pandemia, objetivando analisar como ocorreu a assistência aos alunos com deficiência visual, visto que necessitam de estratégias de acessibilidade e utilização de novas metodologias mediadas por tecnologias digitais, diante do cenário vigente, onde são disponibilizadas pelas universidades. Para isso, utilizou-se a revisão bibliográfica de publicações científicas e documentos que forneceram subsídios teóricos 
para essa pesquisa, bem como conteúdos recentes que abordam a pandemia e a educação (LEITE et al., 2020).

Pelo trabalho, nota-se que a educação dos estudantes com deficiência visual, advinda das Tecnologias de Informação e Comunicação, pode ser uma opção com resultados satisfatórios para aqueles que já têm contato com a internet e fazem uso de recursos assistivos, tais como programas de leitura de tela e conversão de textos em áudio. Entretanto, esses fatores não excluem alguns obstáculos como a descrição de imagens, dificuldade em acompanhar as aulas e os materiais usados simultaneamente, e sobretudo, a ausência de qualificação dos docentes, visto que muitas vezes eles não são preparados para atender as especificidades desse público e nem para o uso da tecnologia a fim de promover a inclusão. Assim, é necessário capacitar esses profissionais para que possam utilizar dessa tecnologia, como mediação, frente às dificuldades encontradas, identificando que a modalidade não-presencial precisa, urgentemente, se adequar às necessidades de cada indivíduo e providenciar os recursos indispensáveis para a inclusão nesse âmbito (LEITE et al., 2020).

As plataformas utilizadas devem oferecer mecanismos de acessibilidade compatíveis com as necessidades dos estudantes com deficiência visual, identificadas pela própria universidade, como recursos de ampliação de tela, teclados e mouses adaptados. Dessa forma, no Ambiente Virtual de Aprendizagem o uso de tecnologias assistivas se mostra o principal meio de inclusão, visto que elas podem ser um instrumento mediador do processo de aprendizagem. A iniciativa das universidades, ao utilizarem essas ferramentas, tem como objetivo promover autonomia e independência desses estudantes ao produzir vídeos que os ensinem a utilizar as plataformas disponíveis para o ensino remoto, com materiais digitalizados ou em braille, bem como a melhor maneira de conduzir as aulas para atender as diversidades do público (LEITE et al., 2020).

\subsection{Shimazaki, Menegassi e Fellini (2020): Ensino remoto para alunos surdos em tempos de pandemia}

$\mathrm{Na}$ educação, com o isolamento social devido à pandemia, o Estado do Paraná aderiu a forma remota como ferramenta de ensino, e, concomitantemente, se preocupou com o ensino e aprendizado de seus alunos surdos. Ademais, contando com o cadastro de 402 mil alunos e 41 mil professores, o sistema educacional do Paraná aborda as aulas em vídeo por meio do Google Classroom, por um canal no YouTube e pela disponibilização de milhares de downloads pelo aplicativo "Aula Paraná", além de transmissões na televisão pela emissora RIC-Record (SHIMAZAKI; MENEGASSI; FELLINI, 2020).

Com base nisso, a presente pesquisa exploratória, foi desenvolvida aplicando-se remotamente, três questionários e uma entrevista com uma pedagoga, três alunos e cinco professores. Para tanto, pautou-se na Teoria Histórico-Cultural e no Dialogismo, teoria da linguagem, para analisar os registros obtidos, a fim de compreender como ocorre o atendimento escolar por ensino remoto a discentes surdos durante a pandemia da Covid19. O estudo se desenvolveu em três etapas distintas e sequenciais, onde iniciou-se com a identificação do local da pesquisa, posteriormente o levantamento da população e amostras do estudo e por último a aplicação empírica sobre os rgistros coletados (SHIMAZAKI; MENEGASSI; FELLINI, 2020).

Destacando-se a relevância da escola bilíngue como espaço de identificação para os alunos surdos nos aspectos linguístico, social e cultural, bem como a importância do domínio da língua de sinais pelo professor, os resultados alcançados pela pedagoga e professores apontam os desafios encontrados no atendimento remoto no Estado do Paraná, dentre os quais, o ensino remoto revela-se um entrave na elaboração de aulas, 
assim como a vulnerabilidade econômica de alguns discentes, que interfere no acesso às atividades remotas, além da falta de auxílio familiar para os estudos. Dessa forma, tais circunstâncias promovem a ausência do contato social escolar, o que compromete o progresso linguístico e social desses alunos (SHIMAZAKI; MENEGASSI; FELLINI, 2020).

\subsection{Böck, Gomes e Beche (2020): A experiência da deficiência em tempos de pandemia: acessibilidade e ética do cuidado}

Tendo por base uma conversa com dez sujeitos com deficiência, este trabalho objetivou compreender quais as mudanças e adversidades do isolamento social em suas vidas, as quais dispuseram-se a refletir acerca da experiência vivenciada pelo isolamento social devido à pandemia. O estudo trata de uma investigação emancipatória de teor qualitativo, advertindo para a indispensabilidade de cuidado e atenção pelas políticas públicas, além de práticas profissionais eficazes a fim de assegurar dignidade e inclusão para esses indivíduos (BÖCK; GOMES; BECHE, 2020).

Relatou-se que existem divergências nas características de vivência das pessoas de acordo com sua deficiência, sendo ela auditiva, visual ou física ou marcas biológicas, e principalmente no contexto social de cada uma. Destacando a importância da atenção e o cuidado das políticas públicas e das próprias práticas dos profissionais, uma vez que o entendimento de deficiência apresentado no texto vincula-se com as teorias feministas da militância das pessoas com deficiência. Nesse modelo é destacada a relevância da diferenciação das deficiências entre lesão e deficiência, onde a lesão é abordada como uma marca biológica e a deficiência como uma experiência social e/ou relacional. (BÖCK; GOMES; BECHE, 2020).

A metodologia utilizada, para o desenvolvimento do grupo dos participantes, foi o método de bola de neve, o qual é um processo contínuo de coleta de dados e informações, onde procura utilizar das redes sociais dos entrevistados para fornecer mais contatos potenciais ao pesquisador. Utilizou-se a inclusão por conveniência intencional, ou seja, buscou-se por pessoas com características estabelecidas a priori que se encaixassem com o estudo, onde deu-se prioridade por pessoas com deficiências que possuíssem ou estivessem cursando o nível superior e trabalhassem, vivenciando o isolamento social e 0 trabalho remoto (BÖCK; GOMES; BECHE, 2020).

As análises ocorreram conforme os critérios do Modelo Social da Deficiência diante da crítica feminista, a qual tem como princípio a visão de que a sociedade seja estruturada em atribuir a deficiência como uma questão pública, não restrita exclusivamente à rede privada e à família. Após o contato com os participantes, algumas categorias analíticas emergiram, destacando-se a interdependência, a experiência interseccional da deficiência, o capacitismo, a ética do cuidado, a acessibilidade e a representatividade (BÖCK; GOMES; BECHE, 2020).

\subsection{Diálogos reflexivos}

Observa-se que o distanciamento social, devido à pandemia, trouxe grandes impactos, principalmente na área da educação, no que concerne a busca por metodologias e estratégias capazes de promover um aproveitamento educacional satisfatório aos alunos com deficiências, como apresentado no trabalho de Bonotto et al. (2020). Dentre elas, a tecnologia se mostra essencial no papel de estimular a independência e participação social da pessoa com deficiência, como também apontam Leite et al. (2020). Nesse sentido, a Comunicação Aumentativa e Alternativa, subárea da Tecnologia Assistiva, tratada no estudo de Bonotto et al. (2020), foi ao encontro dos objetivos de desenvolver essa 
autonomia e participação enquanto, simultaneamente, corroborou para a superação de obstáculos na comunicação e acesso às informações vigentes, idem destacado por Leite et al. (2020), embora, este tenha sido pontual em tratar de recursos para facilitar o acesso de alunos com deficiência visual no Ensino Superior.

Além disso, no estudo de Leite et al. (2020), por mais que os autores evidenciam a importância dos recursos tecnológicos para promover a inclusão de alunos com deficiência visual no Ensino Superior, os mesmos são enfáticos ao pontuarem que estes apresentam algumas limitações que podem vir a dificultar a acessibilidade, acentuando-se, ainda mais, com o despreparo dos professores frente às tecnologias, perspectiva também destacada por Silva (2020), suscitando a necessidade de preparação urgente desses profissionais. Diante disso, nota-se que o distanciamento social imposto pela pandemia trouxe a urgência de uma nova maneira de ensinar, onde o ensino remoto ressignificou as metodologias educacionais até então empregadas, tal como pôde ser observado nos estudos de Silva (2020), Bonotto et al. (2020) e Shimazaki, Menegassi e Fellini (2020). Entretanto, os alunos com deficiência visual precisam de uma abordagem específica, ideia também apresentada por Shimazaki, Menegassi e Fellini (2020) ao abordarem a acessibilidade de alunos surdos no Ensino Superior, a qual demanda esforço das instituições educacionais e dos docentes, em que devem identificar esses fatores e se comprometerem em prol de um processo inclusivo que favoreça a permanência desses estudantes na sua graduação.

No estudo de Shimazaki, Menegassi e Fellini (2020) é dado foco à acessibilidade de alunos com surdez no Ensino Superior durante a pandemia. Os resultados apresentam uma insatisfatoriedade acerca da aprendizagem remota dos mesmos, cujos fatores financeiros, limitações sistêmicas da instituição, falta de traquejo dos docentes com a tecnologia e dos pais, no que concerne o acompanhamento dos filhos, e o próprio isolamento social dificultam a educação dos alunos surdos. Tal cenário é corroborado pelos estudos de Silva (2020) e de Leite et al. (2020), embora não tenham tratado da deficiência auditiva, especificamente. Com isso, é essencial que sejam elaborados mecanismos de inclusão, personalizados de acordo com a necessidade específica de cada aluno, como apontado anteriormente por Leite et al. (2020). Esse entrave traz em seu bojo a necessidade social de se repensar a inclusão, uma vez que a sua efetividade não depende, exclusivamente, de leis, mas do compromisso de todos os cidadãos e setores sociais, notadamente na educação, como enseja pensar o estudo de Böck, Gomes e Beche (2020) e de Silva, Bins e Rozek (2020).

A seu turno, Böck, Gomes e Beche (2020), pontuam que a deficiência não é uma fatalidade, a qual deve ser compreendida e tratada como uma questão pública a fim de promover a inclusão, devendo ser pensada para além das políticas públicas no intuito de construir a autonomia e independência dos estudantes. Além do mais, a experiência vivenciada devido a pandemia acarretou a busca e a criação de diferentes metodologias de ensino, igualmente destacado por Bonotto et al. (2020), mostrando que pode ser o começo para um novo olhar, novas compressões e a ponte para quebra de paradigmas impostos envoltos das capacidades das pessoas com deficiências, como revelam Silva, Bins e Rozek (2020). Outrossim, o ERE trouxe mudanças abruptas no sistema educacional vigente, promovendo descompasso no ensino e aprendizagem, requerendo um plano político, social e científico a fim de promover transformações concretas na educação para uma efetiva inclusão dos alunos com deficiências nessa nova estratégia educacional.

Depreende-se, em suma, que mesmo com as falhas apresentadas pelas tecnologias empregadas no ERE, no processo de promover inclusão, estas se mostram imprescindíveis para tanto. Entretanto, os aspectos negativos levantados pelos artigos, que se revelam como entrave nesse processo, dizem respeito ao aspecto econômico dos estudantes e de suas famílias, a inexperiência dos professores frente às tecnologias, a falta dos pais no 
acompanhamento dos filhos, assim como o próprio isolamento, o qual prejudica o desenvolvimento social dos alunos, como dito anteriormente. Outro fator é quanto a especificidade de cada deficiência, uma vez que requer trato diferenciado, o que exige ainda mais preparo e suporte por parte dos profissionais da educação. Além disso, este cenário de fragilidade promove um solavanco reflexivo quanto a real promoção de inclusão das pessoas com deficiências antes e durante a pandemia, exigindo medidas efetivas para que elas possam gozar de seu direito à educação.

\section{CONSIDERAÇÕES FINAIS}

O contexto pandêmico vigente proporcionou mudanças educacionais severas, especialmente aos discentes com deficiências, pois conferiu, aos profissionais da educação, novas formas de conduzirem suas aulas, além de proporcionar novas experiências de aprendizagem aos alunos. Diante disso, objetivou-se, inicialmente, realizar um mapeamento sistemático da literatura a partir de artigos científicos sobre a inclusão no $E R E$, tendo em vista que o Brasil possui uma vasta legislação acerca dos direitos às pessoas com deficiências. Entretanto, a inclusão não é uma prática totalmente efetivada, o que vem sendo intensificado com a mudança do ensino presencial para o ERE, apesar do seu progresso e a superação de algumas barreiras ao longo do tempo.

A busca realizada nas bases de dados selecionadas retornou poucos artigos publicados. Apesar disso, a análise feita permitiu colocar em pauta o que vem sendo realizado para promover inclusão no ambiente remoto. Os estudos destacam a importância dos recursos tecnológicos como principais facilitadores, embora com algumas limitações, além do mais, eles elencam aspectos desfavoráveis, como dificuldades de professores com a tecnologia e dos pais para lidarem com os filhos, questões financeiras, o próprio isolamento e as especificidades de cada deficiência que precisam ser levadas em consideração.

À guisa de conclusão, a reflexão resultante da interconexão entre os artigos, leva a pensar na urgência de uma mudança drástica na forma como esses alunos são acolhidos na educação, especialmente no ERE. Com isso, a ação concomitante entre o Governo, as instituições e a própria sociedade é o primeiro passo para superar os impactos excludentes da pandemia na educação. Ademais, apesar deste trabalho ter tido a pretensão de realizar um mapeamento inicial sobre o processo de inclusão no ERE, pesquisas futuras se fazem pertinentes a fim de que possam ser desenvolvidas novas análises sobre essa temática, sugerindo-se que outras bases de dados possam ser acessadas.

\section{REFERÊNCIAS}

BARBOSA, Otavio Luis; CUNHA, Paulo Giovani Moreira da. Pandemia e a precarização do direito ao acesso à educação. Revista Pet Economia UFES, Vitória, v. 1, n. 1, p. 3336, jul. 2020. Disponível em: https://periodicos.ufes.br/peteconomia/article/view/31745. Acesso em: 01 out. 2020.

BEZERRA, Kelianny Pinheiro et al. Ensino remoto em universidades públicas estaduais: o futuro que se faz presente. Research, Society and Development, Vargem Grande Paulista, v. 9, n. 9, p. e359997226-e359997226, 2020. Disponível em: https://rsdjournal.org/index.php/rsd/article/view/7226/6517. Acesso em: 01 out. 2020.

BÖCK, Geisa Letícia Kempfer; GOMES, Débora Marques; BECHE, Rose Clér Estivalete. A experiência da deficiência em tempos de pandemia: acessibilidade e ética do cuidado. 
Criar Educação, Criciúma, v. 9, n. 2, p. 122-142, 2020. Disponível em: http://periodicos.unesc.net/criaredu/article/view/6049/5403. Acesso em: 01 out. 2020.

BONOTTO, Renata; CARDOSO, Eduardo; MARTINS, Daianne Serafim; CORREA, Igor. Oportunidades de aprendizagem com apoio da Comunicação Aumentativa e Alternativa em tempos de Covid-19. Revista Ibero-Americana de Estudos em Educação, Araraquara, v. 15, n. 4, p. 1730-1749, 2020. Disponível em: https://periodicos.fclar.unesp.br/iberoamericana/article/view/13945/9550. Acesso em: 01 out. 2020.

BRASIL. Constituição (1988). Constituição da República Federativa do Brasil. Brasília: Senado Federal, 1988. Disponível em:

http://www.planalto.gov.br/ccivil_03/Constituicao/Constituicao.htm. Acesso em: 01 out. 2020.

BRASIL. Institui a Lei Brasileira de Inclusão da Pessoa com Deficiência (Estatuto da Pessoa com Deficiência). Lei № 13.146, de 6 de julho de 2015. Diário Oficial da União, Brasília, 06 jul. 2015. Disponível em:

http://www.punf.uff.br/inclusao/images/leis/lei_13146.pdf. Acesso em: 22 out. 2020.

BRASIL. Decreto o 9.465, de 2 de janeiro de 2019. Diário Oficial da União, Brasília, 02 jan. 2019. Seção: 1 - Extra. Disponível em: https://www.in.gov.br/materia//asset_publisher/Kujrw0TZC2Mb/content/id/57633286. Acesso em: 13 out. 2020.

COSTA, Roberta et al. Ensino de enfermagem em tempos de Covid-19: como se reinventar nesse contexto? Texto \& Contexto-Enfermagem, Florianópolis, v. 29, p. 01 03, 2020. Disponível em: https://www.scielo.br/pdf/tce/v29/pt_1980-265X-tce-29e20200202.pdf. Acesso em: 01 out. 2020.

ESTORNIOLO FILHO, José. EndNote basic: guia de uso. São Paulo: Biblioteca/CIR FSP/USP, 2018. Disponível em: http://www.biblioteca.fsp.usp.br/wpcontent/uploads/2018/03/EndNote_basic_12.pdf. Acesso em: 22 out. 2020.

GLAT, Rosana; FERNANDES, Edicléa Mascarenhas. Da educação segregada à educação inclusiva: uma breve reflexão sobre os paradigmas educacionais no contexto da Educação Especial brasileira. Revista Inclusão, Brasília, v. 1, n. 1, p. 01-06, 2005. Disponível em: http://forumeja.org.br/sites/forumeja.org.br/files/Da\%20Educa\%C3\%A7\%C3\%A30\%20Seg regada\%20\%C3\%A0\%20Educa\%C3\%A7\%C3\%A30\%20Inclusiva.pdf. Acesso em: 01 out. 2020.

HODGES, Charles; MOORE, Stephanie; LOCKEE, Barb; TRUST, Torrey; BOND, Aaron. As diferenças entre o aprendizado online e o ensino remoto de emergência. Revista da Escola, Professor, Educação e Tecnologia, Parnamirim, v. 2, p. 01-12, 2020. Disponível em: https://educa.ibge.gov.br/jovens/materias-especiais/20787-uso-de-internettelevisao-e-celular-no-brasil.html. Acesso em: 01 out. 2020. 
INSTITUTO BRASILEIRO DE GEOGRAFIA E ESTATÍSTICA. Uso de internet, televisão e celular no Brasil. Rio de Janeiro, 2018. Disponível em: https://educa.ibge.gov.br/jovens/materias-especiais/20787-uso-de-internet-televisao-ecelular-no-brasil.html. Acesso em: 01 out. 2020.

INSTITUTO NACIONAL DE ESTUDOS E PESQUISAS EDUCACIONAIS ANÍSIO TEIXEIRA. Ministério da Educação. Censo escolar 2018 revela crescimento de 18\% nas matrículas em tempo integral no ensino médio, 2019. Disponível em: http://portal.inep.gov.br/artigo/-/asset_publisher/B4AQV9zFY7Bv/content/censo-escolar2018-revela-crescimento-de-18-nas-matriculas-em-tempo-integral-no-ensinomedio/21206. Acesso em: 01 out. 2020.

LANA, Raquel Martins et al. Emergência do novo coronavírus (SARS-CoV-2) e o papel de uma vigilância nacional em saúde oportuna e efetiva. Cadernos de Saúde Pública, Rio de Janeiro, v. 36, n. 3, p. 01-05, 2020. Disponível em:

https://www.scielosp.org/article/csp/2020.v36n3/e00019620/pt/. Acesso em: 01 out. 2020.

LEITE, Laís et al. Impactos da Covid-19 na graduação da pessoa com deficiência visual. Revista Encantar - Educação, Cultura e Sociedade, Bom Jesus da Lapa, v. 2, p. 01-14, jan./dez. 2020. Disponível em:

https://www.revistas.uneb.br/index.php/encantar/article/view/8863. Acesso em: 01 out. 2020.

MINISTÉRIO DA EDUCAÇÃO. Conselho Nacional de Educação. Diretrizes Nacionais para a Educação Especial na Educação Básica. Parecer Conselho Nacional de Educação/Conselho de Educação Básica 17/2001. Brasília, 2001. Disponível em: http://portal.mec.gov.br/seesp/arquivos/pdf/parecer17.pdf. Acesso em: 01 out. 2020.

MINISTÉRIO DA EDUCAÇÃO. Secretaria de Educação Especial. Política Nacional de Educação Especial na Perspectiva da Educação Inclusiva. Inclusão: revista da educação especial, Brasília, v. 4, n. 1, p. 01-61, jan./jun. 2008. Disponível em: http://portal.mec.gov.br/seesp/arquivos/pdf/revinclusa05.pdf. Acesso em: 01 out. 2020.

MINISTÉRIO DA EDUCAÇÃO. Secretaria de modalidades especializadas, 2020.

Disponível em: http://portal.mec.gov.br/modalidades-especializadas-de-educacao. Acesso em: 01 out. 2020.

OLIVEIRA, Eleilde de Sousa et al. A educação a distância (EaD) e os novos caminhos da educação após a pandemia ocasionada pela Covid-19. Brazilian Journal of Development, São José dos Pinhais, v. 6, n. 7, p. 52860-52867, 2020.

ROCHA, Fabio Gomes; NASCIMENTO, Bruno Alves Reis; NASCIMENTO, Ester Fraga Vilas Boas Carvalho do. Um modelo de mapeamento sistemático para a educação. Cadernos da FUCAMP, Monte Carmelo, v. 17, n. 29, p. 01-06, 2018. Disponível em: http://www.fucamp.edu.br/editora/index.php/cadernos/article/view/1180/858. Acesso em: 01 out. 2020. 
ROCHA, Julimar Santiago et al. Inclusão escolar de jovens e adultos com deficiências: Ações gestoras necessárias. Brazilian Journal of Education, Technology and Society, v.11, n.3, p.506-521, jul./set. 2018. Disponível em:

http://brajets.com/index.php/brajets/article/view/481. Acesso em: 01 out. 2020.

SARAIVA, Karla; TRAVERSINI, Clarice; LOCKMANN, Kamila. A educação em tempos de Covid-19: ensino remoto e exaustão docente. Práxis Educativa, Ponta Grossa, v. 15, p. 01-24, 2020. Disponível em:

https://revistas.apps.uepg.br/index.php/praxiseducativa/article/view/16289/209209213529. Acesso em: 01 out. 2020.

SENHORAS, Eloi Martins. Coronavírus e educação: análise dos impactos assimétricos. Boletim de Conjuntura (BOCA), Boa vista, v. 2, n. 5, p. 128-136, 2020b. Disponível em: https://revista.ufrr.br/boca/article/view/Covid-19Educacao. Acesso em: 01 out. 2020.

SENHORAS, Eloi Martins. Novo coronavírus e seus impactos econômicos no mundo. Boletim de conjuntura (BOCA), Boa Vista, v. 1, n. 2, p. 39-42, 2020a. Disponível em: https://revista.ufrr.br/boca/article/view/Coronavirus. Acesso em: 01 out. 2020.

SHIMAZAKI, Elsa Midori; MENEGASSI, Renilson José; FELLINI, Dinéia Ghizzo Neto. Atendimento ensino remoto para alunos surdos em tempos de pandemia. Práxis Educativa, Ponta Grossa, v. 15, p. 01-17, 2020. Disponível em: https://revistas.apps.uepg.br/index.php/praxiseducativa/article/view/15476/209209213432. Acesso em: 01 out. 2020.

SILVA FILHO, José Gomes da; MONTALVÃO NETO, Alberto Lopo; ROCHA, Gustavo Gomes Siqueira da. A produção acadêmica sobre o ensino remoto emergencial (ERE) em meio a pandemia da Covid-19: perspectivas e tendências. In: Escritos de educação [recurso eletrônico]: perspectivas e tendências / organizadores: Jenerton Arlan Schütz ... [et al.]. - Cruz Alta: llustração, 2020, v. 2.

SILVA, José Rogério da. Desafios de estudantes e professores de Bayeux-PB, durante a pandemia. REDE-Revista Diálogos em Educação, Anicuns, v. 1, n. 1, p. 127-144, 2020. Disponível em:

http://www.faculdadeanicuns.edu.br/ojs/index.php/revistadialogosemeducacao/article/view /41/12. Acesso em: 01 out. 2020.

SILVA, Karla Wunder da; BINS, Katiuscha Lara Genro; ROZEK, Marlene. A educação especial e a covid-19: aprendizagens em tempos de isolamento social. Interfaces Científicas-Educação, v. 10, n. 1, p. 124-136, 2020. Disponível em: https://periodicos.set.edu.br/educacao/article/view/8914. Acesso em: 16 out. 2020.

TODOS PELA EDUCAÇÃO. Educação inclusiva: conheça o histórico da legislação sobre inclusão, 2020. Disponível em: https://todospelaeducacao.org.br/noticias/conhecao-historico-da-legislacao-sobre-inclusao/. Acesso em: 01 out. 2020. 